American Journal of Pharmaceutical Education 2020; 84 (10) Article 8001.

\title{
RESEARCH
}

\section{Opioid-Related Education Provided by Continuing Education Divisions at US Pharmacy Schools}

\author{
Mandy L. Renfro, PharmD, ${ }^{\mathrm{a}}$ Leticia R. Moczygemba, PhD, ${ }^{\mathrm{a}}$ Jennifer Baumgartner, PharmD, \\ Glen Baumgart, PhD, ${ }^{a}$ Lucas G. Hill, PharmD ${ }^{\mathrm{a}}$ \\ ${ }^{a}$ The University of Texas at Austin College of Pharmacy, Austin, Texas \\ ${ }^{\mathrm{b}}$ Accreditation Council for Pharmacy Education, Chicago, Illinois \\ Submitted January 24, 2020; accepted May 17, 2020; published October 2020.
}

Objective. To quantify the number and type of new opioid-related continuing pharmacy education (CPE) activities offered by continuing education divisions (CEDs) at US schools and colleges of pharmacy from 2015 through 2018, and to determine the number of pharmacists who completed opioid-related CPE activities.

Methods. Data was derived from the database of CPE activities maintained by the Accreditation Council for Pharmacy Education (ACPE), which is the sole accreditation agency for all providers of $\mathrm{CPE}$, including pharmacy schools. Data were filtered to include only pharmacy school CPE providers. A search for six keywords (opiates, opioids, pain, pain management, drug overdose, and opioid antagonist) was conducted for the years 2015-2018. The data extracted included title of the CPE activity, contact hours, activity type, activity format, and the number of pharmacists who participated in the activity. Descriptive statistics were used. A content analysis of activity titles was performed.

Results. Overall, the CEDs of US schools and colleges of pharmacy delivered 20.3\% of all ACPE-approved opioid-related CPE activities from 2015-2018. A total of 1,237 unique opioid-related CPE activities were identified. The number of new CPE activities increased from 249 in 2015 to 297 in 2016 to 349 in 2017, then decreased to 342 in 2018. These activities reached 149,373 pharmacists and were most commonly affiliated with the following keywords: opioids (34.8\%) and pain management $(30.2 \%)$.

Conclusion. The opioid epidemic creates an opportunity for pharmacists to increase their role in public health, but education and training are necessary. The study findings indicate that many pharmacists participate in opioid-related CPE provided by ACPE-accredited CEDs of pharmacy schools. This number is likely to increase as a growing number of states are beginning to require opioid-related CPE for pharmacist license renewal.

Keywords: opioids, naloxone, continuing pharmacy education

\section{INTRODUCTION}

From 1997 through 2017, more than 700,000 people died from drug overdoses in the United States, and $68 \%$ of the 70,200 drug overdose deaths in 2017 involved an opioid. ${ }^{1}$ In addition to the high mortality rate from drug overdoses, the economic burden of the opioid epidemic has exceeded $\$ 1$ trillion and is projected to cost another $\$ 500$ billion by $2020 .^{2,3}$ This cost includes lost wages and productivity, increased health care costs, and increased use of the criminal justice system. ${ }^{3}$ As a result, the opioid epidemic was declared a public health emergency in 2017

Corresponding Author: Mandy L. Renfro, The University of Texas at Austin College of Pharmacy, 2409 University Ave., Austin, TX 78712. Tel: 832-331-3839. Email:

mandyrenfro@utexas.edu by the US Department of Health and Human Services (DHHS). ${ }^{4}$

Since DHHS' declaration of the opioid public health emergency and subsequent release of the 5-Point Strategy to Combat the Opioid Crisis in 2017, the Centers for Disease Control and Prevention has worked to support and implement strategies to mitigate the opioid crisis. ${ }^{4}$ The 5-Point Strategy includes improving access to prevention, treatment, and recovery services, including medication-assisted treatment. ${ }^{5}$ Other aims focus on pain and addiction research, timely public health data reporting, and increased access to naloxone. ${ }^{5}$

Naloxone, an opioid antagonist, is recognized as the drug-of-choice for reversing an acute opioid overdose. ${ }^{6}$ Pharmacists are highlighted in the DHHS 5-Point Strategy as a member of the health care team, who as a member 


\section{American Journal of Pharmaceutical Education 2020; 84 (10) Article 8001.}

of the health care team, is authorized to dispense naloxone via a standing order by independent prescriptive authority, or by a collaborative practice agreement, depending on state rules and regulations. ${ }^{5,7-9}$ This aligns with a resolution endorsed by the National Association of Boards of Pharmacy (NABP) titled, "Increasing Patient Access to Naloxone Rescue Kits." 10 Pharmacists act as "readily accessible member[s] of the healthcare team and play a major role in preventing prescription drug abuse," according to the NABP resolution issued in $2016 .{ }^{10}$ Naloxone access laws at the state-level, which allow pharmacists to dispense naloxone, have been associated with increased naloxone dispensing and, in turn, a reduction in opioid overdose deaths. ${ }^{11-13}$

For pharmacists to be effectively engaged in this role, proper education and training are necessary. Many pharmacy schools across the nation have recognized that training in and out of the classroom is needed for future pharmacists to fully understand the impact of the opioid epidemic and they have started to provide training for students within the Doctor of Pharmacy (PharmD) curriculum. ${ }^{14-16}$ Less is known regarding the number of practicing pharmacists who have been educated on the opioid crisis and new laws surrounding naloxone prescribing and dispensing. In fact, numerous studies have found pharmacists to be in need of further education regarding this issue. ${ }^{17-21}$ In response, some states are adding opioid-related education as a requirement for license renewal. As of October 2019, at least seven states require pharmacists to complete at least one hour of continuing pharmacy education (CPE) on the topics of opioids or naloxone dispensing in order to qualify for annual or biennial license renewal. ${ }^{22-28}$ Additionally, three states require pharmacists to complete CPE related to controlled substances, and two states require them to complete at least one hour of CPE on pain management. ${ }^{29-33} \mathrm{CPE}$ requirements may be fulfilled by any Accreditation Council for Pharmacy Education (ACPE) accredited providers (eg, accredited colleges or schools of pharmacy, national, state, or local professional pharmacy associations, as well as individual health systems).

The primary objective of this research was to determine the number and type of new opioid-related CPE activities offered from 2015-2018 by ACPE-accredited continuing education divisions (CEDs) at US schools and colleges of pharmacy. Another purpose was to better understand the role of CEDs of pharmacy schools and colleges in developing programs that address emerging public health topics like the opioid epidemic. The number of pharmacist participants in opioid-related CPE activities over the four-year period is also described. This is the first study to use a national database to examine CPE activities.

\section{METHODS}

The ACPE database of continuing pharmacy education (CPE) activities was the data source for this study. The CPE activities for the years 2015 through 2018 were included. Variables extracted for the study included CPE activity title, provider-type (ie, college of pharmacy), contact hours, type of activity (application or knowledgebased), format of activity (home-study or live), and the keywords identified by CPE providers. Only college of pharmacy providers with ACPE accreditation status were included in this study. The CPE providers self-selected keywords from a list; thus, and keywords that were related to opioid programming were used for this study. Activities with at least one of the following key terms were included in the study: opiates, opioids, pain, pain management, drug overdose, and opioid antagonist. Because pain and pain management are broad categories that may overestimate opioid-related CPE activities, the subset of keywords that were specific to opioids (ie, opiates, opioids, drug overdose, and opioid antagonist) was also examined. Keywords were assigned by the provider of the activity and were not mutually exclusive for a given activity. To determine the extent of opioid-related CPE provided by colleges of pharmacy, the percentage of ACPE-accredited opioid-related CPE provided by schools and colleges of pharmacy was calculated. This is a cumulative percentage of all opioid-related programs from 20152018 (ie, some programs are offered in multiple years and included in the cumulative percentage). To determine the number of new opioid-related CPE activities conducted from 2015-2018, the researchers first counted the total number of activities for each keyword. Because an activity may have had more than one keyword, duplicates across all keywords were deleted to obtain the unique number of new activities for each keyword per year. Descriptive statistics (means, frequencies, percentages) were used to describe the number of activities per keyword, overall activities per year, activity format, activity type, number of contact hours per CE activity, number of pharmacists who completed each activity, and number of CEDs offering CPE activities per year.

Using the same ACPE database of pharmacy CPE activities, two researchers performed a qualitative content analysis of the titles of each CPE activity title by year to identify and describe the topic areas conveyed by titles for each keyword. This was done to gain insight into the type of topic areas emphasized in each activity. The researchers independently reviewed titles and then had a consensus meeting to agree upon coding. A second consensus meeting was held to conduct a final review of coding and collapse categories with small numbers of 


\section{American Journal of Pharmaceutical Education 2020; 84 (10) Article 8001.}

titles (eg, harm reduction into naloxone, opioid toxicity into opioids). A title could be assigned to more than one category (eg, pain management and opioids) when applicable. The University of Texas at Austin Institutional Review Board approved this study.

\section{RESULTS}

Of the 145 accredited colleges of pharmacy in the United States, 56\% $(n=81)$ had ACPE-accredited CEDs at the time of data acquisition in September 2019. The number of CEDs with a new opioid and/or pain management-related activity in the ACPE database was similar from year to year, with 62 in 2015, 68 in 2016, 67 in 2017, and 68 in 2018. This indicates that over $75 \%$ of colleges of pharmacy with CEDs used their platform to deliver home or live study activities on at least one of the keywords queried each year. Of the CPE acivities found using the four opioid-related keywords, opiates, opioids, drug overdose, and opioid antagonist, only 42, 52, 57, and 59 CEDs of US pharmacy schools, respectively, were represented. Thus, 210 or approximately $52 \%$ to $73 \%$ of all US pharmacy school CEDs provided opioid-specific content from 2015 to 2018.

Overall, college of pharmacy providers delivered $20.3 \%$ of 12,723 ACPE-accredited opioid-related CPE activities from 2015-2018. The number of new opioid- related CPE activities offered by the CEDs at US schools and colleges of pharmacy CEDs had increased since 2015. In 2015, 249 unique activities were offered among all keywords. In 2016, the number of activities increased by $19 \%$. The number of offerings increased again from 2016 to 2017 by $17.5 \%$. From 2017 to 2018 , the number of unique activities decreased by $2 \%$. When looking at activity numbers by the subset of specific opioid-related keywords (opiates, opioids, drug overdose, opioid antagonist), there were 100, 139, 207, and 246 activities in years 2015, 2016, 2017, and 2018 respectively. (Table 1).

Activities were found to be most commonly affiliated with the following keywords: opioids $(34.8 \%)$, pain management $(30.2 \%)$, and pain (18.6\%). One of the lowest keywords was opioid antagonist $(2.5 \%)$; however, this keyword became available for providers to choose in 2017 , so we were only able to retrieve two years of data. A summary of the number of activities conducted by keyword and year, as well as the number of pharmacists completing activities by year are presented in Table 1 .

The average number of contact hours for activities was 1.0 to 2.1 hours for each keyword. Most activities $(86.7 \%)$ were offered as live programming as opposed to home-study. Additionally, across each individual keyword and year observed, knowledge-based activities were more common than application-based activities, comprising

Table 1. Opioid-Related Continuing Pharmacy Education Activities Provided by the Continuing Education Divisions of US Schools and Colleges of Pharmacy

\begin{tabular}{|c|c|c|c|c|c|}
\hline & 2015 & 2016 & 2017 & 2018 & $\overline{\text { Total }}$ \\
\hline \multicolumn{6}{|l|}{ Opiates } \\
\hline Activities, No. ${ }^{\mathrm{a}}$ & 14 & 13 & 15 & 20 & 62 \\
\hline Pharmacists, No. ${ }^{\mathrm{b}}$ & 1,160 & 4,476 & 1,123 & 1,140 & 8,339 \\
\hline \multicolumn{6}{|l|}{ Opioids } \\
\hline Activities, No. ${ }^{\text {a }}$ & 74 & 109 & 173 & 205 & 562 \\
\hline Pharmacists, No. ${ }^{b}$ & 9,235 & 18,347 & 15,464 & 12,231 & 55,367 \\
\hline \multicolumn{6}{|l|}{ Pain } \\
\hline Total activities ${ }^{\mathrm{a}}$ & 68 & 66 & 74 & 76 & 301 \\
\hline Number of pharmacists ${ }^{b}$ & 4,237 & 2,526 & 3,931 & 3,823 & 14,517 \\
\hline \multicolumn{6}{|l|}{ Pain Management } \\
\hline Total activities ${ }^{\mathrm{a}}$ & 131 & 139 & 160 & 57 & 487 \\
\hline Number of pharmacists ${ }^{b}$ & 7,655 & 7,441 & 6,358 & 10,075 & 31,529 \\
\hline \multicolumn{6}{|l|}{ Drug Overdose } \\
\hline Total activities ${ }^{\mathrm{a}}$ & 34 & 48 & 42 & 37 & 161 \\
\hline Number of pharmacists ${ }^{b}$ & 6,412 & 17,377 & 8,677 & 5,292 & 37,758 \\
\hline \multicolumn{6}{|l|}{ Opioid Antagonist } \\
\hline Total activities ${ }^{\mathrm{a}}$ & $\mathrm{n} / \mathrm{a}$ & $\mathrm{n} / \mathrm{a}$ & 18 & 22 & 40 \\
\hline Number of pharmacists ${ }^{b}$ & $\mathrm{n} / \mathrm{a}$ & $\mathrm{n} / \mathrm{a}$ & 507 & 1,356 & 1,863 \\
\hline Total unique activities ${ }^{\mathrm{c}}$ & 249 & 297 & 349 & 342 & 1,237 \\
\hline
\end{tabular}




\section{American Journal of Pharmaceutical Education 2020; 84 (10) Article 8001.}

$86.9 \%$ of all activities. Details on contact hours, activity setting, and activity type can be found in Table 2 .

Activity titles most commonly contained some mention of pain management $(25.6 \%)$ and/or opioids (25.5\%) (Table 3). Only 108 (6.7\%) were coded to the naloxone category. Although it was not possible to identify activities by keyword opioid antagonist prior to 2017, this gives an indication of naloxone-related activities based on activity title. Under keywords pain and pain management, several activities were coded as condition, practice setting, or medication-specific trainings. Other prevalent content categories include law, medicationassisted treatment/opioid use disorder, and addiction and drug abuse.

\section{DISCUSSION}

We found that more than $70 \%$ of colleges of pharmacy with an ACPE-accredited CED were engaged in opioid-related CPE, which shows that they are being responsive to creating timely programming that aligns with emerging public health topics. A total of 1,237 unique activities were offered from 2015 through 2018, with 149,373 pharmacist participants. The majority of activities $(83.6 \%)$ included the keyword opioids, pain, or pain management.

As of May 2019, there were more than 300,000 licensed pharmacists in the United States. ${ }^{34}$ Although we were able to determine the number of opioid-related $\mathrm{CPE}$ activities conducted and the total number of pharmacists who participated in each, there was no way of knowing whether individual pharmacist learners completed more than one activity during the study period. As more states begin to require pharmacists to complete opioid-related
CPE for license renewal, the number of pharmacists completing CPE activities is likely to increase. The total number of participants in CPE activities $(149,373)$ conducted by pharmacy school CEDs also does not reflect pharmacists who may have received CE credit from another provider, such as a state or national pharmacy association.

The role of the pharmacist has changed over time, from that of strictly dispensing drugs to delivering patient care, providing medication and disease state counseling, and conducting public health activities. ${ }^{35,36}$ Because of advocacy efforts, the accreditation and CPE requirements of colleges of pharmacy, and the collaboration efforts between pharmacy and other healthcare professions, pharmacists have helped to address significant public health issues, such as deficits in adult immunization rates, over the past two decades. ${ }^{37}$ Similarly, to combat the opioid epidemic as a part of the health care team, it is essential for every practicing pharmacist to be educated and equipped to do so. Pharmacists across the nation have started this movement by utilizing available prescription drug monitoring programs to help prevent opioid diversion. ${ }^{38}$ To build upon this, pharmacists should also be aware of opioid misuse warning signs, as well as hazardous medication combinations and inappropriate prescribing by providers. ${ }^{38}$ While our study focused on CPE that included content related to opioids, pain, and naloxone, we discovered that US college of pharmacy CEDs are using their platform to address each component mentioned above so that pharmacists may have the comprehensive skillset needed to be effective in their role. The pharmacist numbers also suggest that college of pharmacy CEDs are reaching a large number of pharmacists

Table 2. US School and College of Pharmacy Opioid-Related Continuing Education Activity Contact Hour and Activity Type Data by Keyword

\begin{tabular}{lccccc}
\hline Keyword & $\begin{array}{c}\text { Average Contact } \\
\text { Hours, No. }\end{array}$ & $\begin{array}{c}\text { Home Study } \\
\text { Activity, }{ }^{\mathbf{a}} \text { No. (\%) }\end{array}$ & $\begin{array}{c}\text { Live Activity, }{ }^{\mathbf{b}} \\
\text { No. }(\%)\end{array}$ & $\begin{array}{c}\text { Knowledge- Based } \\
\text { Activity, }{ }^{\mathbf{c}}{ }^{\text {No. }} \mathbf{( \% )}\end{array}$ & $\begin{array}{c}\text { Application- Based } \\
\text { Activity, }{ }^{\mathbf{d}} \text { No. (\%) }\end{array}$ \\
\hline Opiates & 2.06 & $9(14.5)$ & $53(85.5)$ & $57(92)$ & $5(8)$ \\
Opioids & 1.52 & $72(12.8)$ & $490(87.2)$ & $506(90)$ & $56(10)$ \\
Pain & 1.7 & $34(11.3)$ & $267(88.7)$ & $269(89.4)$ & $32(10.6)$ \\
Pain management & 1.7 & $58(11.9)$ & $429(88.1)$ & $403(82.8)$ & $84(17.2)$ \\
Drug overdose & 1.65 & $35(11.7)$ & $126(78.3)$ & $135(83.9)$ & $26(16.1)$ \\
Opioid Antagonist & 1.63 & $6(15)$ & $34(85)$ & $32(80)$ & $8(20)$ \\
\hline
\end{tabular}

\footnotetext{
${ }^{a}$ Accreditation Council for Pharmacy Education (ACPE) defines home study activities as enduring materials that are printed, recorded or computer assisted instructional materials that do not provide for direct interaction between faculty and learners

${ }^{\mathrm{b}}$ ACPE defines live activities as those that provide for direct interaction between faculty and learners and may include lectures, symposia, live teleconferences, workshops, etc

${ }^{\mathrm{c}}$ ACPE defines knowledge-based CPE activities as being primarily constructed to transmit knowledge (ie, facts). The minimum amount of credit for these activities is 15 minutes or 0.25 contact hour

${ }^{\mathrm{d}}$ ACPE defines application-based CPE activities as being primarily constructed to apply the information learned in the time allotted. The minimum amount of credit for these activities is 60 minutes or 1.0 contact hour
} 


\section{American Journal of Pharmaceutical Education 2020; 84 (10) Article 8001.}

Table 3. Summary of Content Analysis of Continuing Pharmacy Education Program Titles to Describe Frequency of Topic Areas Among Keywords

\begin{tabular}{|c|c|c|c|c|}
\hline \multirow[b]{2}{*}{ Topic Area } & \multicolumn{4}{|c|}{ Year } \\
\hline & 2015 & 2016 & 2017 & 2018 \\
\hline \multicolumn{5}{|l|}{ Keyword: Opiates } \\
\hline Addiction/drug abuse & 3 & 2 & 4 & 3 \\
\hline Naloxone ${ }^{a}$ & 1 & 3 & 1 & 0 \\
\hline Opioids $^{\mathrm{b}}$ & 4 & 4 & 3 & 10 \\
\hline Pain management & 6 & 2 & 2 & 5 \\
\hline Other $^{\mathrm{f}}$ & 3 & 1 & 5 & 12 \\
\hline \multicolumn{5}{|l|}{ Keyword: Opioids } \\
\hline Addiction/drug abuse & 8 & 13 & 17 & 12 \\
\hline Naloxone $^{\mathrm{a}}$ & 7 & 13 & 12 & 29 \\
\hline Opioids $^{\mathrm{b}}$ & 30 & 55 & 84 & 109 \\
\hline Pain management & 16 & 17 & 32 & 20 \\
\hline Other ${ }^{\mathrm{f}}$ & 4 & 15 & 22 & 63 \\
\hline \multicolumn{5}{|l|}{ Keyword: Pain } \\
\hline Addiction/drug abuse & 2 & 3 & 2 & 3 \\
\hline Condition specific ${ }^{c}$ & 8 & 18 & 7 & 22 \\
\hline Practice setting specific ${ }^{d}$ & 6 & 10 & 8 & 2 \\
\hline Pain management & 36 & 32 & 25 & 28 \\
\hline Other $^{\mathrm{f}}$ & 10 & 6 & 10 & 5 \\
\hline \multicolumn{5}{|l|}{ Keyword: Pain Management } \\
\hline Addiction/drug abuse & 6 & 5 & 5 & 2 \\
\hline Condition specific ${ }^{c}$ & 34 & 28 & 29 & 13 \\
\hline Medication specific ${ }^{\mathrm{e}}$ & 3 & 10 & 8 & 1 \\
\hline Opioids $^{\mathrm{b}}$ & 18 & 23 & 17 & 5 \\
\hline Pain management & 57 & 59 & 51 & 24 \\
\hline Practice setting specific ${ }^{\mathrm{d}}$ & 13 & 1 & 7 & 5 \\
\hline Other $^{\mathrm{f}}$ & 20 & 13 & 11 & 5 \\
\hline \multicolumn{5}{|l|}{ Keyword: Drug Overdose } \\
\hline Addiction/drug abuse & 2 & 5 & 3 & 3 \\
\hline Naloxone ${ }^{\mathrm{a}}$ & 2 & 9 & 12 & 4 \\
\hline Opioids ${ }^{b}$ & 2 & 1 & 9 & 7 \\
\hline Overdose & 0 & 5 & 2 & 6 \\
\hline Other $^{f}$ & 13 & 7 & 7 & 7 \\
\hline \multicolumn{5}{|l|}{ Keyword: Opioid Antagonist } \\
\hline Addiction/drug abuse & $\mathrm{n} / \mathrm{a}$ & $\mathrm{n} / \mathrm{a}$ & 1 & 2 \\
\hline Naloxone $^{a}$ & $\mathrm{n} / \mathrm{a}$ & $\mathrm{n} / \mathrm{a}$ & 3 & 6 \\
\hline Opioids ${ }^{\mathrm{b}}$ & $\mathrm{n} / \mathrm{a}$ & $\mathrm{n} / \mathrm{a}$ & 1 & 4 \\
\hline Other $^{\mathrm{f}}$ & $\mathrm{n} / \mathrm{a}$ & $\mathrm{n} / \mathrm{a}$ & 0 & 17 \\
\hline
\end{tabular}

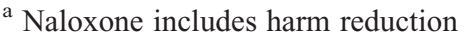

${ }^{\mathrm{b}}$ Opioids includes opioid withdrawal, opioid epidemic, opioid toxicity

${ }^{c}$ Condition specific includes back pain, cancer, geriatrics, neuropathic pain, migraine, acute pain, post-surgical

${ }^{d}$ Practice setting specific includes community, palliative care, hospice, post-surgical, ICU, primary care, ED, long term care

${ }^{\mathrm{e}}$ Medication specific includes ketamine, methadone, marijuana, controlled substances

${ }^{\mathrm{f}}$ Other includes law, medication assisted treatment, opioid use disorder, overdose prevention, drug diversion, patient safety, prescription monitoring program via their CPE activities and can have a key role in education related to public health crises.

Recent studies have shown that, while many pharmacy chains across the nation have adopted naloxone dispensing protocols and standing orders, there is still a gap in pharmacists' education about and confidence in performing these tasks. ${ }^{20,38,39}$ There have been five statewide analyses of pharmacy-based naloxone availability, all demonstrating gaps in access. ${ }^{39-43}$ While our data analysis reveals that a large set of CPE activities were offered on opioids and related topics over the past several years, a small number of titles were coded to the naloxone content category $(6.7 \%)$. This is a gap in pharmacist education, and the number of pharmacists who complete naloxone training will likely increase over time, especially as more states require pharmacists to complete $\mathrm{CPE}$ related to this topic for license renewal. ${ }^{22-27}$ This trend reflects the fact that dissemination and implementation of strategies to address public health issues, such as the opioid epidemic, which includes pharmacist education and training, take time and it may be years before the strategies are fully adopted across the profession. ${ }^{44}$

This study had several limitations. First, the available data were reported as total annual numbers of activities and learners per de-identified ACPE accredited provider, rather than as number of learners per individual activity. Thus, we were unable to discern how many pharmacists were trained by a particular activity, or if one pharmacist completed more than one activity during the study timeframe. In addition, pharmacist learners reported by keyword were included from all programming available for that year and previous years as long as the program was not yet expired. Another limitation of this project is that only titles and keywords of activities in the ACPE database were accessible. Having access to additional details, such as activity learning objectives, may have helped us further examine the extent to which opioid-related topics were included in CPE categories such as pain management. To mitigate this, we used activity titles to perform a qualitative content analysis to identify which titles were relevant. However, misclassification bias may have occurred if an activity with a keyword such as pain management did not include opioid-related content. An additional limitation is that although the keyword opioid antagonist became available in 2017 , there may have been a lag in CE providers becoming aware of and using new keywords such as this. Also, programs that were approved prior to 2017 were available for up to three years, which means that the term opioid antagonist may have been applicable to some of these programs. Thus, the 


\section{American Journal of Pharmaceutical Education 2020; 84 (10) Article 8001.}

term opioid antagonist is likely relevant to more programs than are reported. Finally, our analysis did not assess CE provided by other entities such as ACPEaccredited providers who work in partnership with colleges of pharmacy, employers, health systems, national/ state pharmacy organizations, or private interest groups. Because of this, we are unable to draw any significant conclusions regarding the percentage of total pharmacists in the United States trained on these key topics. Further, educational programming that is offered by ACPEaccredited providers, such as employer training, is not captured in this study.

\section{CONCLUSION}

Most CEDs at schools and colleges of pharmacy have been responsive to calls to provide opioid-related programming, a priority public health topic. Continuing education divisions should continue to focus on ways to expand their platform and access to pharmacist alumni networks, along with internal expert faculty clinicians to aid in the development of new, up-to-date content on public health issues such as the opioid epidemic. Although CEDs are providing opioid-related education, it is not known how the education ultimately impacts public health outcomes. In the case of opioid-related training, future research should focus on examining how $\mathrm{CPE}$ impacts outcomes, such as the impact of opioid-related counseling on patient knowledge and naloxone dispensing patterns.

\section{ACKNOWLEDGMENTS}

Portions of this paper were presented at the Southern Pharmacy Administration Conference 2018 in Auburn, AL, the American Pharmacists Association 2019 Annual Meeting in Seattle, WA, and the University of Texas at Austin College of Pharmacy Research Day 2019 in Austin, TX.

\section{REFERENCES}

1. Opioid Overdose: Understanding the Epidemic. Centers for Disease Control and Prevention. https://www.cdc.gov/drugoverdose/ epidemic/index.html. Published December 19, 2018. Accessed September 24, 2020.

2. Robeznieks A. Understanding the Opioid Epidemic's Economic Toll. American Medical Association. https://www.ama-assn.org/ delivering-care/opioids/understanding-opioid-epidemic-s-economictoll. Published October 15, 2018. Accessed September 24, 2020.

3. Litton S. Economic Toll of Opioid Crisis in U.S. Exceeded \$1 Trillion Since 2001. Altarum. https://altarum.org/news/economictoll-opioid-crisis-us-exceeded-1-trillion-2001. Published February 13, 2018. Accessed September 24, 2020.

4. What is the U.S. Opioid Epidemic? U.S. Department of Health and Human Services. https://www.hhs.gov/opioids/about-the-epidemic/. Updated January 22, 2019. Accessed September 24, 2020.
5. Strategy to Combat Opioid Abuse, Misuse, and Overdose: A Framework Based on the Five Point Strategy. U.S. Department of Health and Human Services. https://www.hhs.gov/opioids/sites/ default/files/2018-09/opioid-fivepoint-strategy-20180917-508compliant. pdf. Accessed September 24, 2020.

6. Opioid Overdose Reversal with Naloxone (Narcan, Evzio). National Institute on Drug Abuse. https://www.drugabuse.gov/ related-topics/opioid-overdose-reversal-naloxone-narcan-evzio. Updated February 2020. Accessed Semptember 24, 2020.

7. Naloxone Overdose Prevention Laws. Prescription Drug Abuse Policy System. http://pdaps.org/datasets/laws-regulatingadministration-of-naloxone-1501695139. Updated July 1, 2017. Accessed September 24, 2020.

8. Bailey AM, Wermeling DP. Naloxone for opioid overdose prevention: pharmacists' role in community-based practice settings. Ann Pharmacother. 2014;48(5):601-606. doi:10.1177/ 1060028014523730.

9. Olivia EM, Christopher MLD, Wells D, et al. Opioid overdose education and naloxone distribution: development of the veterans health administration's national program. J Am Pharm Assoc. 2017;57(2):S168-S179.e4. doi:10.1016/j.japh.2017.01.022. 10. Increasing Patient Access to Naloxone Rescue Kits (Resolution 112-2-16). National Association of Boards of Pharmacy. https:// nabp.pharmacy/increasing-patient-access-to-naloxone-rescue-kitsresolution-112-2-16/. Published June 6, 2016. Accessed September 24, 2020.

11. Abouk R, Pacula RL, Powell D. Association between state laws facilitating pharmacy distribution of naloxone and risk of fatal overdose. JAMA Intern Med. 2019 May 6. doi:10.1001/ jamainternmed.2019.0272.

12. McClellan C, Lambdin BH, Ali MM, et al. Opioid-overdose laws association with opioid use and overdose mortality. Addict Behav. 2018;86:90-95. doi:10.1016/j.addbeh.2018.03.014.

13. Xu J, Davis CS, Cruz M, Lurie P. State naloxone access laws are associated with an increase in the number of naloxone prescriptions dispensed in retail pharmacies. Drug Alc Dep. 2018;189:37-41. doi:10.1016/j.drugalcdep.2018.04.020.

14. Schartel A, Lardieri A, Mattingly A, Feemster AA. Implementation and assessment of a naloxone-training program for first-year student pharmacists. Curr Pharm Teach Learn. 2018; 10(6):717-722. doi:10.1016/j.cptl.2018.03.016.

15. Hill LG, Sanchez JP, Laguado SA, Lawson KA. Operation naloxone: overdose prevention service learning for student pharmacists. Curr Pharm Teach Learn. 2018;10(10):1348-1353. doi:10.1016/j.cpt1.2018.07.010.

16. Panther SG, Bray BS, White JR. The implementation of a naloxone rescue program in university students. $J$ Am Pharm Assoc. 2017;57(2):S107-S112. doi:10.1016/j.japh.2016.11.002.

17. Freeman PR, Goodin A, Troske S, Strahl A, Fallin A, Green TC. Pharmacists' role in opioid overdose: Kentucky pharmacists' willingness to participate in naloxone dispensing. J Am Pharm Assoc. 2017;57:S28-33. doi:10.1016/j.japh.2016.12.064.

18. Thompson EL, Rao PSS, Hayes C, Purtill C. Dispensing naloxone without a prescription: survey evaluation of Ohio pharmacists. J Pharm Pract. 2019;32(4):412-421. doi:10.1177/ 0897190018759225.

19. Do V, Behar E, Turner C, Geier M, Coffin P. Acceptability of naloxone dispensing among pharmacists. J Pharm Pract. 2018. doi:10.1177/0897190018798465.

20. Thornton JD, Lyvers E, Scott VGG, Dwibedi N. Pharmacists' readiness to provide naloxone in community pharmacies in West 


\section{American Journal of Pharmaceutical Education 2020; 84 (10) Article 8001.}

Virginia. J Am Pharm Assoc. 2017;57(2S):S12-S18.e4. doi:10.1016/ j.japh.2016.12.070.

21. Melaragni F, Levy C, Pedrazzi J, Andersen M. Assessing pharmacists' readiness to dispense naloxone and counsel on responding to opioid overdoses. $J$ Am Pharm Assoc.

2019;59(4):550-554.e2. doi:10.1016/j.japh.2019.04.012.

22. Continuing Education - Pharmacists. Texas State Board of Pharmacy. https://www.pharmacy.texas.gov/infocist/continue.asp. Accessed May September 24, 2020.

23. Pharmacist Information. New Mexico Pharmacists Association. https://www.nmpharmacy.org/page-1722241. Accessed September 24, 2020.

24. New Continuing Education Requirements for 2019. Mississippi Board of Pharmacy. https://www.mbp.ms.gov/pages/new-

continuing-education-requirement-for-2019.aspx. Accessed September 24, 2020.

25. New Jersey Requirements. Licensure Renewal Requirements. Rutgers Ernest Mario School of Pharmacy. https://pharmacy. rutgers.edu/programs/continuing-education/licensure-renewalrequirements/. Accessed September 24, 2020.

26. Continuing Education and Professional Development. Pennsylvania Pharmacists Association. https://www.papharmacists. com/page/CE_Requirements. Accessed September 24, 2020.

27. Naloxone Prescribing for Pharmacists. North Dakota Board of Pharmacy. https://www.nodakpharmacy.com/naloxone.asp.

Accessed September 24, 2020.

28. Vermont Pharmacy Continuing Education (CE) Requirements. Western Schools. https://www.westernschools.com/pharmacy/ vermont/requirements/. Accessed September 24, 2020.

29. 2500 Board of Pharmacy. Title 24 Regulated Professions and Occupations Delaware Administrative Code. http://regulations. delaware.gov/AdminCode/title24/2500.pdf. Accessed September 24, 2020.

30. Pharmacist. Continuing Education (CE) Requirements. Florida Board of Pharmacy. https://floridaspharmacy.gov/renewals/ pharmacist/. Accessed September 24, 2020.

31. Continuing Education. South Carolina Board of Pharmacy.

Labor Licensing Regulation. https://1lr.sc.gov/bop/ce.aspx. Accessed September 24, 2020.

32. Oregon Secretary of State. Board of Pharmacy Chapter 855:Division 1. Continuing Pharmacy Education. https://secure.sos. state.or.us/oard/displayDivisionRules.action?selectedDivision= 3969 Updated March, 2019. Accessed September 24, 2020.

33. Continuing Education Requirements. Michigan Pharmacists Association. https://www.michigan.gov/documents/lara/ LARA_Pharmacy_CE_Brochure_4-11_376434_7.pdf Accessed September 24, 2020.
34. Occupational Employment and Wages, May 2019. U.S. Bureau of Labor Statistics. United States Department of Labor. https:// www.bls.gov/oes/current/oes291051.htm. Updated July 6, 2020. Accessed September 24, 2020.

35. Giannitrapani KF, Glassman PA, Vang D, et al. Expanding the role of clinical pharmacists on interdisciplinary primary care teams for chronic pain and opioid management. BMC Fam Pract. 2018;19:107. doi:10.1186/s12875-018-0783-9.

36. The Role of the Pharmacist in Public Health. American Public Health Association. https://www.apha.org/policies-and-advocacy/ public-health-policy-statements/policy-database/2014/07/07/13/05/ the-role-of-the-pharmacist-in-public-health. Published November 8 , 2006. Accessed September 24, 2020.

37. Hogue MD, Grabenstein JD, Foster SL, Rothholz MC. Pharmacist involvement with immunizations: a decade of professional advancement. J Am Pharm Assoc (2003). 2006;46(2):168-182. doi:10.1331/154434506776180621. 38. Compton WM, Jones CM, Stein JB, Wargo EM. Promising roles for pharmacists in addressing the U.S. opioid crisis. Res Soc Adm Pharm. 2019;15(8):910-916. doi:10.2016/j.sapharm.2017. 12.009 .

39. Evoy KE, Hill LG, Groff L, et al. Naloxone accessibility without a prescriber encounter under standing orders at community pharmacy chains in Texas. JAMA. 2018;320(18):1934-1937. doi:10.1001/ jama.2018.15892.

40. Meyerson BE, Agley JD, Davis A, et al. Predicting pharmacy naloxone stocking and dispensing following a statewide standing order, Indiana 2016. Drug Alcohol Depend. 2018;188:187-192. doi:10.1016/j.drugalcdep.2018.03.032

41. Graves RL, Andreyeva E, Perrone J, Shofer FS, Merchant RM, Meisel ZF. Naloxone availability and pharmacy staff knowledge of standing order for naloxone in Pennsylvania pharmacies. J Addict Med. 2019;13(4):272-278. doi:10.1097/ADM.0000000000000492. 42. Puzantian T, Gasper JJ. Provision of naloxone without a prescription by California pharmacists 2 years after legislation implementation. JAMA. 2018;320(18):1933-1934. doi:10.1001/ jama.2018.12291.

43. Guadamuz JS, Alexander GC, Chaudhri T, Trotzky-Sirr R, Qato DM. Availability and Cost of Naloxone Nasal Spray at Pharmacies in Philadelphia, Pennsylvania, 2017. JAMA Netw Open. 2019;2(6): e195388. Published 2019 Jun 5. doi:10.1001/jamanetworkopen. 2019.5388

44. Mathis SM, Hagemeier N, Hagaman A, Dreyzehner J, Pack RP. A dissemination and implementation science approach to the epidemic of opioid use disorder in the United States. Curr HIV/AIDS Rep. 2018;15(5):359-370. doi:10.1007/s11904-0180409-9. 